\title{
CREATIVE DISCLOSURE - FEATURE OF CREATIVE ACCOUNTING
}

\author{
Dumitru Matiş ${ }^{1}$ \\ Alina Beattrice Vladu ${ }^{2} *$ \\ Dan Dacian Cuzdriorean ${ }^{3}$
}

ABSTRACT: The purpose of this research is to approach creative disclosure as a feature of creative accounting. Also known in the literature as impression management, this demarche can be found in corporate annual report under forms of distortion of narratives of numerical and graph manipulation. Little is known about the potential effects and consequences of this kind of manipulation in the practical side of accounting and on decisions made by annual report users. Creative accounting presented under all its forms of manifestation can directly affect the profit and loss account and also the balance sheet and it is also related to measurement or disclosure, the latter referring to the extent of to the method of presentation. Since disclosure is also related to credibility of accounting profession.

After assessing the area approached we developed a theoretical framework for creative disclosure.

Key words: creative disclosure, disclosure quality, disclosure credibility

JEL codes: $M 41$

\section{Introduction}

Courtis (2002) highlighted the importance of approaching such an item of research by the following: "The accountancy profession should...take constructive steps to understand the ramifications of narratives and visual techniques that contribute towards perception engineering" (2002: 444).

Even if the author discuss about the potential of narratives and visual techniques as part of impression management or creative disclosure, many other different types have been identified as occurring in corporate annual reports. Even if the exact effects were not approached empirically, by recurring to those demarches is not considered to be fair (Courtis, 2002). Connected to one of the most important item of accounting (e.g. communication), disclosure management could be easily comprised in the area of creative accounting techniques based on the fact that the result or consequence is similar even if the path is different.

The importance of such a topic of research can be in this respect sustained by the communication component, an important segment of an accountant's job and also a major responsibility. Since the forms or creative disclosure are potential subtle can easily go undetected by the users of accounting information. Given the role of annual reports in decision process making, the users of accounting information can be unknowingly mislead since they can make poor investment choices, all based on impression management tools that are creating a perfect image that serves subjective decisions.

\footnotetext{
1 Babeş-Bolyai University, Faculty of Economics and Business Administration, Cluj-Napoca, e-mail: dumitru.matis@econ.ubbcluj.ro

2 Babeş-Bolyai University, Faculty of Economics and Business Administration, Cluj-Napoca, e-mail: beattrice.vladu@econ.ubbcluj.ro

3 Babeş-Bolyai University, Faculty of Economics and Business Administration, Cluj-Napoca, e-mail: dan.cuzdriorean@econ.ubbcluj.ro
} 
Given the increased role of financial statements in the decisions process making, is important to indentify the consequences of such creative demarches and the effects results from manipulation of annual reports.

\section{Theoretical framework for sustaining our research question}

The output of accounting is considered to be the most important one when it comes to the process of decision making as we asserted before. The manner in which accounting information is disclosed or presented to users of accounting information is also extremely important based on the fact that creative disclosure gained a lot of attention. Further, the way accounting information is interpreted by the users of accounting information can be judged based on the ability to present it by the preparers and based on their experience. In this respect, objectivity of accounting information is crucial since it should be elaborated under the TFV requirements (Vladu and Gro anu, 2011). The above refers to fair accounting items likewise at items of unfair accounting.

Unfair accounting components were documented in the literature under different typologies and interpretations starting with fundamental research stream represented by economic acknowledged theories (the most important ones approached above) and also by empirical research stream (Smith 1992:4-221; Mulford and Comiskey 2002, 2005; Ronen and Yaari, 2010; Jones, 2011). All the above are referring to creative accounting techniques other than creative disclosure, but the reason that were approached is related to the management incentives mechanism exposed, that is reflected in connection with creative disclosure.

What all the above studies have in common is the fact that management accounting manipulation cannot be eliminated. In this respect the best way to deal with it is to know and assess it under all its forms of manifestation. Since the users of accounting information become in the recent years more sophisticated (Ronen and Yaari, 2010) the gain for accounting manipulation also had to deal with assessment of gain and cost on average form such manipulation, confirming the conceit of Watts and Zimmerman (1986).

Since corporate annual reports provide a comprehensive source of information over the past corporate of companies, demarches are conducted based on management desire to facilitate the confirmation, revision and formation of readers' expectations about a company in which this category has an interest (Courtis 1998: 459).

When related to usefulness of the information provided by the financial statements as a whole for decision making, it will depend on the accuracy, reliability and understandability comprised (Courtis, 1995, 1996) based on the fact that creative disclosure is a reality (Lee, 1994). Comprising the manipulation of information to portray a particular image, normally aimed at creating a more favorable view of a company's performance than is warranted (Beattie and Jones 2002), creative disclosure involves no objectivity, affecting in this respect the credibility of the accounting profession (Clatworthy and Jones 2001; Courtis 2004).

Some of the reasons that support our scientific demarche were the following: getting to know and be able to assess creative disclosure features; users of accounting information have the right to be informed and in this respect creative accounting data can have an informativeness impact; the ease of employment of creative disclosure; various implications assessment (e.g. conservatism, accounting regulations frameworks vulnerability; ethical issues are only some of them).

Creative accounting existence has important implications as we stated above. Ethical ones in this respect are considered the most important since the root for manipulative behavior is represented by the lack of ethics (Cummings, 2007). Economic consequences attached to aggressive forms of creative accounting cannot be negligible (e.g. Enron case), the credibility of the accounting profession also can be attached to it and the list has various directions that can be followed.

Based on the above we developed the following research question:

- What is the scope of creative disclosure? 
By assessing the above research question we intent to draw attention to creative disclosure effects by explaining its demarches of manifestation. For a facile understanding we have developed the research path by comprising a theoretical framework, approached in the discussions segment.

\section{Methodology}

In this respect we were interested in choosing a suitable methodology that could enable us to answer the questions above and further to achieve our aim. Since this study is not an empirical study, but a fundamental research we briefly constructed an internal history of the literature. In this respect we identified the authors and papers by "backtracking" them from the recent and also relevant contribution to the literature regarding creative disclosure or impression management area of research.

We identified the theme and the issues approached on the basis of a general sampling of the literature and as implicit methodology adopted it was the inductive methodology that sustain the main idea of the fact that general conclusions regarding the development of a subject are drawn from sampling of literature. Since this study is not an empirical one, the problems associated with the applying of such a method are not found in our study.

The importance of theoretical research is underlined by Kothari (2001) who asserted that: "empirical research is (or should be) informed by theory, since interpretation of empirical analysis is impossible without theoretical guidance".

Ronen and Yaari (2010) underlined the importance of both types of research and concluded that theoretical research benefits from empirical research having the fact that: "an analysis is conducted through modeling, which by definition admits only a few features of reality. The quality of the model depends on whether it captures key features. Empirical research provides information on these features. Moreover, if the empirical findings of different studies agree with each other, then the empirical research enhances the intuition of the theorist, if not, even better, because the theorist now faces the challenge of reconciling conflicting findings" (2010:289).

\section{Discussions based on relevant approaches treated in conjunction with creative disclosure area and proposed conceptual framework}

Creative presentation must be regarded as a complex mechanism that comprises: motives for engaging in manipulation of accounts, types of information disclosed, and types of manipulations strictly connected to presentation of information.

The types of information disclosed comprised two categories: verbal information and numerical information. It is considered to be a part of the following strategies. In regarding of types of manipulations connected to presentation of financial information we summarize the following strategies:

- Using a creative manner to make the text difficult to read;

- Using persuasive language that comprises only positive words and emphasizes positive financial performance;

- Using creative visual manipulation in the way information is presented with the scope of attracting the attention from others items that are important but in the same time are not flattering for the financial performance presented;

- Using performance comparisons that involve choosing the benchmarks that portray current financial performance in the best possible light.

Each one of these strategies are not part of an objective disclosure choice moreover are based on subjectivity and bias as we stated before.

The scope of creative presentation is to present the financial information in the best light possible (or sometimes in a very negative light, depending on the management objectives) by comprising only certain items that flatter the final results. The items that don't portray the desired 
image are omitted from presentation and if there is mandatory to disclose them, will be presented in a very subtle way.

The following figure summarizes the main steps used in order to create a creative presentation or creative disclosure.

Based on our understanding the root for this particular creative disclosure is the management intention to present flattered results according to their objectives. In this respect the so-called in the literature "Pollyanna principle" (Hildebrandt and Snyder, 1988) can be ultimate foundation for this demarche. Above we portrayed a framework for creative disclosure management.

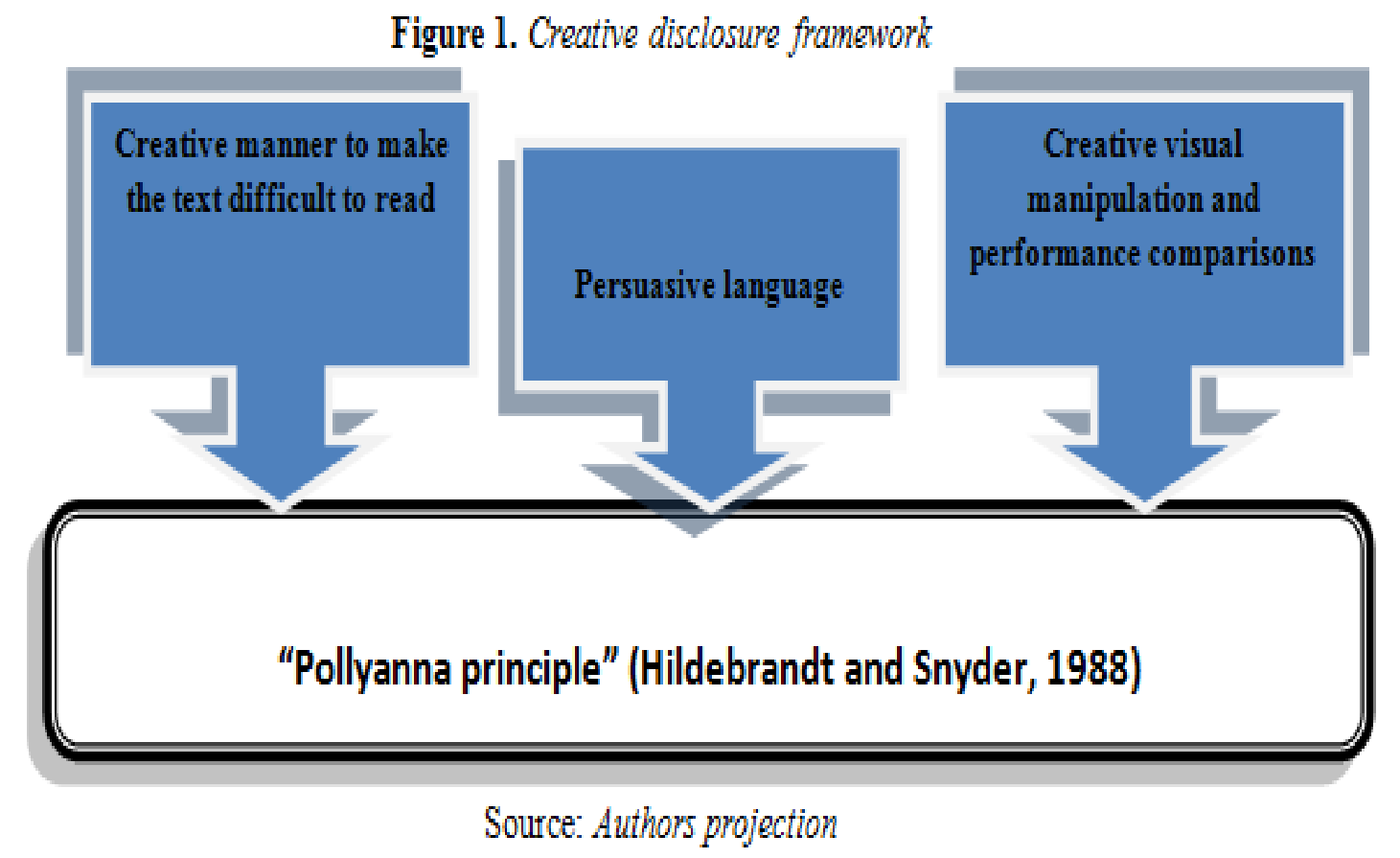

By suing a creative manner to make the text difficult to read, narratives are approached with the scope of providing an image that is more favorable than is warranted (Jones 1996).

As Jones (1996) asserted, if narratives and financial statements presented in corporate annual reports comprised conflicting messages about financial performance, users of accounting information will potentially pay more attention to the words, downplaying the importance of the figures contained in the financial statements. This will have as consequence inappropriate judgments regarding the financial situation of the company, and poor investment decisions by users of this information.

When bad news needs to be transmitted corporations will lose money and reputation. This is the main scope for this kind of creative presentation where firms are willing to spent time and money to ensure that the bad news will be disclosed in the end in a favorable way and will not affect their future image or performances. In this context outside agencies are employed or inside professionals trained to write narrative report sections that have the potential of transmitting the desired message even if this message is not sustain by the economic reality.

Courtis (2004) referring to a creative manner used to make the text of financial presentation difficult to read and interpret, asserted that this particular manner is designed to obscure the intended message, to distract or confuse the readers.

Courtis (1995) discussing about the difficulty to read some corporate reports concluded that only two possibilities can be invoked in such cases by the following: "whether writing which is difficult to read is executed deliberately to mask some unfavorable aspect of corporate behavior, or 
is performed unwittingly out of ignorance". On the other hand Clatworthy and Jones (2001) attribute exclusively the reading difficulty to managerial manipulation since they consider that the lack of skill cannot be invoked in this context since corporate reports are written by professionals. Rutherford (2003) asserted that preparers that are willing to manipulate the user's opinion have the possibility to manage the transparency of financial information by minimizing the clarity of certain items that are disclosed.

Another root for creative accounting appearance is identified by Llewellyn and Milne (2007), as the codification of the accounting language, that "turns out to be a less than perfect solution". It is this particular codification that makes possible for the companies to "stray across the boundary between legal and illegal practice without their "excursions" being readily apparent in the accounts, as scandals like Enron, Worldcom and Parmalat demonstrate". The authors also asserted that code complexity is one of the roots of "creative accounting problem" and more transparency is needed and as a consequence of that this equated with more codification of its language.

Khalifa et al., (2007) approaching the codification of the language used in audit field, asserted the fact that this particular codification of accounting language lay down the public to imagine that accounting texts represent financial realities through a single direction that is not negotiable. The authors pointed out the fact that is not the case and that accounting can be manipulated as a result of the complexity of its practice codes.

Further by using a persuasive language that comprises only positive words and emphasizes positive financial performance also increases the potential to manipulate user's perceptions. In this context is not important "what" firms disclosed but rather "how" is done.

This type of manipulation is known in the literature also under the name of "positive bias" (Lang and Lundholm, 2000) and is not only related to the manner in which disclosures are presented but also in the frequency of the positive or optimistic reports. The study conducted by Lang and Lundholm (2000) found that the frequency of positive disclosure increased substantially before equity public offerings in order to increase the firm's share prices.

One study that was focused on the language used by firms to transmit positive and negative earnings was the study conducted by Yuthas et al. (2002). The authors suggested that firms with earnings surprises use preponderantly items like "sincerity" and "clarity" to emphasize their honesty and trustworthiness, their tone being persuasive in respect of the financial strong performance of the firms.

Enron engaged in this kind of manipulation and used persuasive language based on our understanding. In the Enron's Letter to Shareholders, Annual Report 2000 the language can be easily categorized as persuasive language as we can notice from the following:

- "Enron's performance in $\mathbf{2 0 0 0}$ was a success by any measure, as we continued to outdistance the competition and solidify our leadership in each of our major businesses. In our largest business, wholesale services, we experienced an enormous increase of 59 percent in physical energy deliveries. Our retail energy business achieved its highest level ever of total contract value" (2000:4);

- "During our 15-year history, we have stretched ourselves beyond our own expectations. We have metamorphosed from an asset-based pipeline and power generating company to a marketing and logistics company whose biggest assets are its well-established business approach and its innovative people" (2000: 6-7);

- "Our results put us in the top tier of the world's corporations" (2000:7);

- "We plan to leverage all of these competitive advantages to create significant value for our shareholders" (2000:7).

Adopting the "Pollyanna principle" (e.g. the eternal optimist; concept introduced by Hildebrandt and Snyder, 1988) managers present to financial performance of the firm in the best light possible using only positive words or underlying in an exaggerate manner in some sections of the reports items that favorable their position. 
The creative visual manipulation and performance comparisons comprise two important paths for creative disclosure based on our view.

The way information is disclosed visually speaking has the potential to influence the decisions. Creative visual effects can be used to underlie a part of the corporate report or an item in order to make it more obvious to users (e.g. figures, font style, size of the letters or numbers, color, etc.) (Courtis, 2004).

To create a strong visual effect the ordering of the items of location of them (Bowen et al., 2005) is also important. Where there is willingness to present an item as being very important the first parts of the corporate reports can be chosen for such a demarche.

When the item is considered to minimize the favorable direction that must be created and interpreted under the best light possible, the last parts the corporate reports can be chosen or inserted in the most narrative part of the reports. By choosing to explain or underlie the importance only for some earnings numbers and intentionally omitting the ones that are not flattering the final results involve subjectivity and further manipulation of corporate reports.

We asserted above that the types of information disclosed can be either verbal or numerical.

This particular creative presentation is related to manipulation of numerical disclosures. The main idea is that firms can manipulate the information disclosed using performance comparisons that flatter their performance. This type of manipulation is developed using either inside numerical information or external numerical information.

As regarding of inside numerical information the lowest prior-period comparative benchmark earnings number can be chosen to report in this respect the highest year-on-year increase in earnings (Schrand and Walther, 2000; Cassar, 2001). External numerical information can be constructed from the lowest competitors in a cross sectional analysis of industry performance.

\section{Conclusions, limitation and scope for future research}

Financial statement have the great potential of reaching an audience whose interests and backgrounds for reading them can vary substantially over time, easily and routinely available in a single document (Hooks et al., 2002). The importance associated with them also can follow this particular trend since they are multi-objective and multi-audience (Anderson and Imperia, 1992). Since they contain basic information regarding the company state of affairs, the interest to communicate through them a desired image is even greater.

By comprising financial, narrative and quantitative information, the financial statements are the basis for decision makers along with meeting the disclosure requirements imposed.

Until this point, the importance of them is highlighted. Based on their importance as communication component their role must be assessed close related to the disclosure quality and credibility since company's disclosure can be used not only to communicate trustworthiness. We summarized in this respect some of the facets that point a lack of trustworthiness as: creative manners used in order to make the text difficult to read; persuasive language and creative visual manipulation and performance comparisons tools. Each of them were explained and their connection to creative accounting demarches highlighted. We comprise them in a theoretical framework for a facile understanding under the aegis of "Pollyanna principle" (Hildebrandt and Snyder, 1988).

The analysis of the literature comprised our methodology that can be characterized by high descriptive power and in that particular segment of our study weak normative power and also weak criteria for criticism since our goal was to present a straightforward way of cognitively interpreting the development of our area of research.

In this respect our role was the role of one analyst with low parameters of effective criticism but highly prescriptive and descriptive in order to maintain a high level of credibility in explanations and descriptions comprised in our research. 
A further study will comprise the empirical assessment of each of the creative disclosure demarches under the spectrum of consequences involved in conjunction with: disclosure quality, disclosure credibility, investment decision process, measurement of disclosure quality and further implications for information asymmetry component of the capital.

\section{Acknowledgment}

Investing in people! PhD scholarship, Project co-financed by the European Social Fund, SECTORAL OPERATIONAL PROGRAMME HUMAN RESOURCES DEVELOPMENT 2007 2013, Babeş-Bolyai University, Cluj-Napoca, Romania

\section{References}

1. Anderson, C. J., Imperia, G., 1992. The corporate annual report: A photo analysis of male and female portrayals, The Journal of Business Communication, vol. 29, issue 2, pp. 113 128

2. Beattie, V., Jones, M.J., 2002. Measurement distortion of graphs in corporate reports: an experimental study, Accounting, Auditing \& Accountability Journal, vol. 15, issue 4, pp. 546-64

3. Bowen, R., Davis, A., Matsumoto, D., 2005. Emphasis on pro forma versus GAAP earnings in quarterly press release: Determinants, SEC intervention and market reaction, The Accounting Review, vol. 80, no. 4, pp. 1001-1038

4. Cassar, G., 2001. Self-serving Behaviour and the Voluntary Disclosure of Capital Market Performance, Accounting Research Journal, vol. 14, pp. 126-137

5. Clatworthy, M.A., Jones, M.J., 2001. The Effect of Thematic Structure on the Variability of Annual Report Readability, Accounting, Auditing and Accountability Journal, vol.14, no.3, pp.311-326

6. Core, E., 2001. A review of the empirical disclosure literature: discussion

7. Courtis, J.K., 1995. Readability of annual reports: Western versus Asian evidence, Accounting, Auditing and Accountability Journal, vol. 8, no. 2, pp. 4-17

8. Courtis, J.K., 1996. Disclosure redundancy in annual reports, Accountability and Performance, vol. 2, no. 3, pp. 1-16

9. Courtis, J.K., 2004. Corporate report obfuscation: Artefact or phenomenon?, British Accounting Review, vol. 36, no. 3, pp. 291-312

10. Cummings, L.S., 2007. How to cook your books - A recipe for disaster, Auditing and Accountability Journal, vol. 20, issue 4, pp. 629-630

11. Hooks, J., Coy, D., Davey, H., 2002. The information gap in annual reports, Accounting, Auditing \& Accountability Journal, vol. 15, issue 4, pp. 501-522

12. Kothari, S.P., 2001. Capital markets research in accounting, Journal of Accounting and Economics, vol. 31, pp. 105-231

13. Lee, T., 1994. The changing form of the corporate annual report, The Accounting Historians Journal, vol. 21, issue 1, pp. 215-232

14. Llewellyn, S., Milne, M.J., 2007. Introduction. Accounting as codified discourse, Accounting, Auditing and Accountability Journal, vol. 20, no. 6, pp. 805-824

15. Jones, M., 1996. Readability of annual reports: Western verus Asian evidence - a comment on contextualize, Accounting, Auditing \& Accountability Journal, vol. 9, issue 2, pp. 86

16. Jones, M., 2011. Creative accounting, Fraud and International Accounting Scandals, John Wiley and Sons Ltd., London 
17. Khalifa, R., Sharma, N., Humphrey, C., Robson, K., 2007. Discourse and audit change: transformations in methodology in the professional audit field, Accounting, Auditing and Accountability Journal, vol. 20, no. 6, pp. 825-854

18. Lang, M., Lundholm, R., 2000. Voluntary disclosure during equity offerings: reducing information asymmetry or hyping the stock? Contemporary Accounting Research, vol. 17, pp. 623-662

19. Mulford, C.W., Comiskey, E.E., 2002. The financial numbers game: detecting creative accounting practices, Wiley, New York

20. Mulford, C.W. and Comiskey, E.E., 2005. Creative Cash Flow Reporting: Uncovering Sustainable Financial Performance, John Wiley and Sons INC, New Jersey, pp. xiii, pp. 347

21. Ronen, J., Yaari, V., 2010. Earnings Management. Emerging Insights in Theory, Practice and Research, Springer Science and Business Media LLC., New York, pp. 10-23; 377-384; 389-404; 433-446

22. Rutherford, B.A., 2003. Obfuscation, textual complexity and the role of regulated narrative accounting disclosure in corporate governance, Journal of Management and Governance, vol. 7, pp. 187-210

23. Schrand, C., Walther, B., 2000. Strategic benchmarks in earnings announcements: The selective disclosure of prior-period components, The Accounting Review, vol. 75, no. 2, pp. 151-177

24. Smith, T., 1992. Accounting for Growth: Stripping the Camouflage from Company Accounts, Century Business Publications, London

25. Vladu, A.B., Grosanu, A., 2011. Some insights regarding creative accounting in Romanian accounting environment - regulators, financial auditors and professional bodies opinion, THE Annals of the University of Oradea. Economic Sciences - TOM XX, 2011, ISSN 1582-5450, pp.661-667, available at: http://anale.steconomiceuoradea.ro/volume /2011/analele-universitatii-oradea-seria-stiinte-economice-numarul-1-iulie-2011.pdf

26. Watts, R., Zimmerman, J., 1986. Positive Accounting Theory, Prentice-Hall, Englewood Cliffs, NJ.

27. Yuthas, K., Rogers, R., Dillard, J. F., 2002. Communicative action and corporate annual reports, Journal of Business Ethics, vol. 41, issue 1, pp. 141-157 